\title{
VORLESUNGEN \\ ÜBER \\ NATURPHILOSOPHIE
}

GEHALTEN

IM SOMMER 1901 AN DER UNIVERSITÄT LEIPZIG

VON

\section{WILHELM OSTWALD}

DRITTE VERMEHRTE AUFLAGE

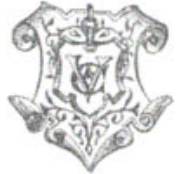

LEIPZIG

VERLAG VON VEIT \& COMP.

1905 
Druck von Metzger \& Wittig in Leipzig. 


\section{ERNST MACH}

\section{GEWIDMET}


